\title{
Erratum to: Psychological Adjustment in Families Affected by Autism Spectrum Disorder
}

\author{
Katherine Whitehead $^{1}$ - Diana Dorstyn ${ }^{1}$. \\ Lynn Ward ${ }^{1}$
}

Published online: 28 September 2015

(C) Springer Science+Business Media New York 2015

\section{Erratum to: J Dev Phys Disabil DOI 10.1007/s10882-015-9446-0}

The authors would like to note an error in the Data Analysis section, Figure 1 heading and Table 3 heading. Each, incorrectly, refer to 'multivariate regression model', 'regression model' and 'multivariate regression analysis'. The correct terms are: 'regression models' and 'multiple regression'. The procedure involved two univariate regression equations, rather than a single multivariate model. This error has no implications for the analyses or the reported results.

The online version of the original article can be found at http://dx.doi.org/10.1007/s10882-015-9446-0.

Lynn Ward

lynn.ward@adelaide.edu.au

1 University of Adelaide, Adelaide, Australia 